\title{
Filling of electronic states and crystal lattice deformation around dislocation wall
}

\author{
R.M.Peleschak \\ Ivan Franko Drogobych State Pedagogical University, \\ 24 I.Franko Str., 293720 Drogobych, Lviv Region, Ukraine \\ Received March 1, 1999, in final form April 2, 1999
}

\begin{abstract}
Within the band model we study the electron redistribution around the dislocation wall depending on the conduction band filling $(0<\bar{n}<1)$ taking into account the electron-deformation coupling. We show that as the conduction band filling $\bar{n}$ increases, the redistribution gets more localized around the dislocation plane. It is established that an increase of the distance between the neighbouring dislocations raises the period of changes in charge density redistribution $\Delta n$ along the dislocation wall, whereas a change in the amplitude of the electron redistribution as a function of the distance to the dislocation plane is smoother.
\end{abstract}

Key words: electron-deformation interaction, dislocation wall

PACS: $61.72 . L k, 68.35 .-p, 68.55 . L n$

Modern electronics is based to a great extent on heterostructures. In the process of growth of such two-dimensional structures at certain conditions a dislocation wall arises due to the incommensurability of the contracted crystal structure parameters [1]. The problem of dislocation belongs to an important field of the solid state physics, namely, to the defect crystal physics.

Electron distribution around an edge dislocation is calculated in [2] taking into account the electron-deformation interaction. It is shown that the distribution essentially depends on the interaction of electrons with the dislocation. Let us consider such a problem for a crystal structure with the dislocation wall. In addition to the intrinsic interest to the problem, its results are of interest for the poligonization process as long as the wall of the periodically arranged edge dislocations describes the structure of the stable low-angle border of slope between grains $[3,4]$.

We consider a crystal with an orbital degenerate conduction band. Mechanical deformation in it produced by an impurity, defects, or dislocation leads to nonuniform displacements of the band on the energy scale. At the same time, the space redistribution of electrons around the deformations and renormalization of the initial 
mechanical deformation occur. The Hamiltonian of the crystal with dislocations has the form $[2-5]$

$$
H=\sum_{i \sigma}\left[\omega+S U\left(\mathbf{r}_{i}\right)\right] c_{i \sigma}^{+} c_{i \sigma}+\sum_{i j \sigma}^{\prime} \lambda_{i j}^{0} c_{i \sigma}^{+} c_{j \sigma}+\frac{1}{2} \sum_{i} K \Omega_{0} U^{2}\left(\mathbf{r}_{i}\right) c_{i \sigma}^{+} c_{i \sigma}+H_{\mathrm{c}} .
$$

Here $c_{i \sigma}^{+}\left(c_{i \sigma}\right)$ is an operator of creation (annihilation) of an electron with spin $\sigma$ in the Wannier state $i ; \omega$ is its energy, and $S$ describes its displacement induced by deformation; $\lambda_{i j}^{0}$ is the mixing integral in a non-deformed state; $K$ is a spring constant; $U\left(\mathbf{R}_{i}\right)=\operatorname{Sp} \hat{U}\left(\mathbf{R}_{i}\right)=\left(\Omega-\Omega_{0}\right) / \Omega_{0}$ is a parameter of the deformation, which is a relative change in the cell volume ( $\Omega_{0}$ is its initial volume); $H_{\mathrm{c}}$ is a Hamiltonian of Coulomb interaction.

Using conditions of mechanical equilibrium of the system [5]

$$
\left\langle\frac{\partial H}{\partial U(\mathbf{r})}\right\rangle=\sigma_{\text {mech }}(\mathbf{r}) V
$$

( $\sigma_{\text {mech }}$ is a mechanical tension, $V$ is the crystal volume), the parameter of the total deformation $U(\mathbf{r})$ can be presented in the form

$$
U(\mathbf{r})=-\frac{S}{K \Omega_{0}} \sum_{\mathbf{k}, \mathbf{k}^{\prime}, \sigma}\left\langle c_{\mathbf{k} \sigma}^{+} c_{\mathbf{k}^{\prime} \sigma}\right\rangle \exp \left(-\mathrm{i}\left(\mathbf{k}-\mathbf{k}^{\prime}\right) \mathbf{r}\right)+U_{\text {mech }}(\mathbf{r})
$$

where the first term is an "electronic" part of deformation $U_{\mathrm{el}}(\mathbf{r})$, and the second one is its mechanical part $U_{\text {mech }}(\mathbf{r})$.

In the case of infinite wall of edge dislocations located in the ZOY plane along the OY axis $d$ apart, $U_{\text {mech }}(\mathbf{r})$ is equal to [7]

$$
U_{\text {mech }}(|x|, y)=\frac{U_{0} \sin (\Theta y)}{\cosh (\Theta|x|)-\cos (\Theta y)}
$$

where $U_{0}=b(1-r \nu) / 2 d(1-\nu), \Theta=2 \pi / d ; \nu$ is a Poisson coefficient; $\mathbf{b}=(b, 0,0)$ is the Burgers vector directed along the OX axis.

From (3) if follows that the calculation of the electron component of deformation is reduced to the calculation of the correlator $\left\langle c_{\mathbf{k} \sigma}^{+} c_{\mathbf{k}^{\prime} \sigma}\right\rangle$

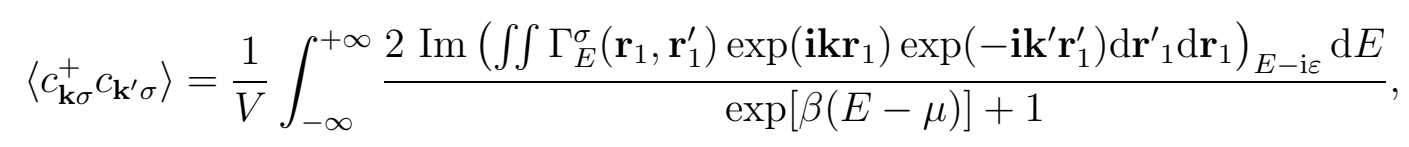

Here $\Gamma_{E}^{\sigma}\left(\mathbf{r}_{1}, \mathbf{r}_{1}^{\prime}\right)$ is a Green function. In the effective mass approximation, an equation for the Green function has the form [5]

$$
\alpha^{*} \nabla_{\mathbf{r}}^{2} \Gamma_{E}^{\sigma}\left(\mathbf{r}, \mathbf{r}^{\prime}\right)-\left[S U(\mathbf{r})-e \varphi(\mathbf{r})+E_{0}-E\right] \Gamma_{E}^{\sigma}\left(\mathbf{r}, \mathbf{r}^{\prime}\right)-\frac{1}{2 \pi} \delta\left(\mathbf{r}-\mathbf{r}^{\prime}\right)=0
$$

where $\alpha^{*}=\hbar^{2} / 2 m^{*}$, and the term with $\varphi(\mathbf{r})$ is an electrostatic energy caused by the charge density redistribution $\Delta n(\mathbf{r})=n(\mathbf{r})-n_{01}$ about the dislocation wall $\left(n_{01}\right.$ is an average total electron concentration of the conduction band [5]. 
Potential $\varphi(\mathbf{r})$ can be obtained from the Poisson equation

$$
\nabla_{\mathbf{r}}^{2} \varphi(\mathbf{r})=\frac{e}{\varepsilon(\mathbf{r}) \varepsilon_{0}}\left[n(\mathbf{r})-n_{01}\right]
$$

The electron conduction band concentration $n(\mathbf{r})$ is connected with the correlator $\left\langle c_{\mathbf{k} \sigma}^{+} c_{\mathbf{k}^{\prime} \sigma}\right\rangle$ by the Fourier transformation

$$
n(\mathbf{r})=\sum_{\mathbf{k}, \mathbf{k}^{\prime}, \sigma}\left\langle c_{\mathbf{k}^{\prime} \sigma}^{+} c_{\mathbf{k} \sigma}\right\rangle \exp \left(-\mathrm{i}\left(\mathbf{k}-\mathbf{k}^{\prime}\right) \mathbf{r}\right)
$$

We expand the Green function in a series in functions $\psi_{n}(\mathbf{r})$

$$
\Gamma_{E}^{\sigma}\left(\mathbf{r}, \mathbf{r}^{\prime}\right)=\frac{1}{2 \pi} \sum_{n} \frac{\psi_{n}^{*}(\mathbf{r}) \psi_{n}\left(\mathbf{r}^{\prime}\right)}{E-\lambda_{n}}
$$

$\psi_{n}(\mathbf{r})$ and $\lambda_{n}$ are solutions of the Schrödinger equation

$$
\left[\nabla_{\mathbf{r}}^{2}-\frac{S}{\alpha^{*}} U(\mathbf{r})+\frac{e}{\alpha^{*}} \varphi(\mathbf{r})\right] \psi_{n}(\mathbf{r})=-\frac{1}{\alpha^{*}}\left(\lambda_{n}-E_{0}\right) \psi_{n}(\mathbf{r}) .
$$

Using (5), (9), equations (3), (8) take the form

$$
\begin{aligned}
& n(\mathbf{r})=\sum_{n} \frac{\psi_{n}^{*}(\mathbf{r}) \psi_{n}(\mathbf{r})}{\exp \left[\beta\left(\tilde{\lambda}_{n}-\mu\right)\right]+1}, \\
& U(\mathbf{r})=-\frac{S}{K} n(\mathbf{r})+U_{\text {mech }}(\mathbf{r}),
\end{aligned}
$$

where $\tilde{\lambda}_{n}=\lambda_{n}-E_{0}$.

$$
\frac{\Omega_{0}}{V} \int n(\mathbf{r}) \mathrm{d} \mathbf{r}=\bar{n}, \quad 0<\bar{n}<n_{01}, \quad \Omega_{0} \leqslant 2 .
$$

Here $\bar{n}$ is an average total number of electrons per lattice cell. Equation (13) allows one to determine the chemical potential.

From the system of equations (7), (10)-(13) we can obtain the potential $\varphi(\mathbf{r})$, parameter of the total deformation $U(\mathbf{r})$, concentration of the conduction band electrons $n(\mathbf{r})$, and chemical potential $\mu$. This system was solved by the successive approximations method at $T=0 \mathrm{~K}$. The mechanical part of the deformation parameter (4) was taken as the initial approximation.

In the case of a crystal system with a large average total electron concentration $\bar{n}_{0}$ (metals, degenerate semiconductors), the electron redistribution $\Delta n(\mathbf{r})$ around a dislocation wall can practically completely compensate the conduction band shift by the energy of additional electrostatic interaction (i.e. $\left.e \varphi(\mathbf{r}) \approx S U_{\text {mech }}(\mathbf{r})\right)$. In the case under consideration, the wave function $\psi_{n}(\mathbf{r})$ as a solution of Schrödinger equation (6) may be presented with a satisfactory accuracy in the plane wave form, i.e.

$$
\psi_{\mathbf{k}}(\mathbf{r})=\frac{1}{\sqrt{V}} \exp [-\mathrm{ikr}]
$$


Substituting summation over $n$ by integration over energy, equation (11) is rewritten as

$$
n(\mathbf{r})=2 \int_{0}^{\mu-E_{0}-S U(\mathbf{r})+e \varphi(\mathbf{r})} \rho\left(E^{\prime}\right) \mathrm{d} E^{\prime},
$$

where $\rho\left(E^{\prime}\right)$ is a density of electron states. In the effective mass approximation it equals

$$
\rho\left(E^{\prime}\right)=\frac{\sqrt{2}}{2 \pi^{2}} \frac{\left(m^{*}\right)^{3 / 2}}{\hbar^{3}} \sqrt{E^{\prime}} .
$$

Substituting (16) into (15) and integrating we obtain

$$
n(\mathbf{r})=\frac{2 \sqrt{2}}{3 \pi^{2}} \frac{\left(m^{*}\right)^{3 / 2}}{\hbar^{3}}\left[\mu+e \varphi(\mathbf{r})-E_{0}+\frac{S^{2}}{K} n(\mathbf{r})-S U_{\text {mech }}(\mathbf{r})\right]^{3 / 2},
$$

(here (12) is taken into account).

Let us expand this solution into a power series in $\left(e \varphi(\mathbf{r})-S U_{\text {mech }}(\mathbf{r})\right)$. In the linear approximation,

$$
\Delta n(\mathbf{r})=R_{S}\left[e \varphi(\mathbf{r})-S U_{\text {mech }}(|x|, y)\right]
$$

In this approximation, taking into account (18), equation (12) may be rewritten as

$$
n_{01}=n_{0}\left[1+\frac{S^{2} n_{01}^{1 / 3} K}{\left(3 \pi^{2}\right)^{2 / 3} \alpha^{*}}\right]
$$

where $n_{0}$ is an initial average concentration of the conduction band electron in the crystal lattice without considering the electron-deformation interaction $(S=0)$;

$$
\begin{aligned}
R_{S} & =\left(\frac{3}{8 \pi^{4}}\right)^{1 / 3} \frac{1}{\alpha^{*}} \frac{\bar{n}^{1 / 3}\left[1+p \bar{n}^{1 / 3}\right]^{1 / 2}}{1-\frac{3}{2} p \bar{n}^{1 / 3}\left[1+p \bar{n}^{1 / 3}\right]^{1 / 2}}, \\
p & =\frac{S^{2}}{\left(3 \pi^{2}\right)^{2 / 3} \alpha^{*} K \Omega_{0}^{1 / 3}} .
\end{aligned}
$$

Then the Poisson equation takes the form

$$
\varepsilon \nabla_{\mathbf{r}}^{2} \varphi(\mathbf{r})-g^{2} \varphi(\mathbf{r})=a U_{\text {mech }}(|x|, y)
$$

where

$$
g^{2}=\frac{e^{2} R_{S}}{\varepsilon_{0}}, \quad a=-\frac{e R_{S} S}{\varepsilon_{0}}
$$

Expanding the functions $\varphi(\mathbf{r})$ and $U_{\text {mech }}(\mathbf{r})$ into the Fourier integrals

$$
\varphi(\mathbf{r})=\frac{\Omega}{(2 \pi)^{3}} \int \varphi(\mathbf{k}) \mathrm{d} \mathbf{k}, \quad U_{\text {mech }}(\mathbf{r})=\frac{\Omega}{(2 \pi)^{3}} \int U_{\text {mech }}(\mathbf{k}) \mathrm{d} \mathbf{k},
$$

and substituting (24) into (22), we obtain an expression for the potential $\varphi(\mathbf{k})$ in the $\mathbf{k}$-space

$$
\varphi(\mathbf{k})=\frac{a}{\varepsilon k^{2}+g^{2}} U_{\text {mech }}(\mathbf{k})
$$


where

$$
U_{\text {mech }}(\mathbf{k})=-\mathrm{i} \frac{8 \pi^{2} \Theta U_{0}}{\Omega} \delta\left(k_{z}\right) \frac{\delta\left(k_{y}-\Theta\right)-\delta\left(k_{y}+\Theta\right)}{\Theta^{2}+k_{x}^{2}}
$$

is the Fourier transform of the deformation potential $U_{\text {mech }}(|x|, y)(4)$ at $|\Theta x| \gg 1$.

Performing the inverse Fourier transformation of $\varphi(\mathbf{k})$, we find an analytical expression for the potential $\varphi(|x|, y)$ in the $\mathbf{r}$-space

$$
\varphi(|x|, y)=-\frac{\Theta b a \sin (\Theta y)}{2 \pi g^{2}} \frac{1-2 \nu}{1-\nu}\left[\mathrm{e}^{-\Theta|x|}-\frac{\Theta}{\sqrt{\Theta^{2}+g^{2} / \varepsilon}} \exp \left(-|x| \sqrt{\Theta^{2}+g^{2} / \varepsilon}\right)\right] .
$$

Substituting the expression (27) and (4) into (18) we obtain the change in the electron redistribution about the plane of the dislocation wall

$$
\Delta n(|x|, y)=A(|x|) \sin (\Theta y) .
$$

Formula (28) can be treated as harmonic oscillations of $\Delta n$ along the OY axis with an amplitude $A(|x|)$

$$
A(|x|)=-\frac{b}{d} \frac{1-2 \nu}{1-\nu} S R_{S} \frac{\Theta}{\sqrt{\Theta^{2}+g^{2} / \varepsilon}} \exp \left(-|x| \sqrt{\Theta^{2}+g^{2} / \varepsilon}\right) .
$$

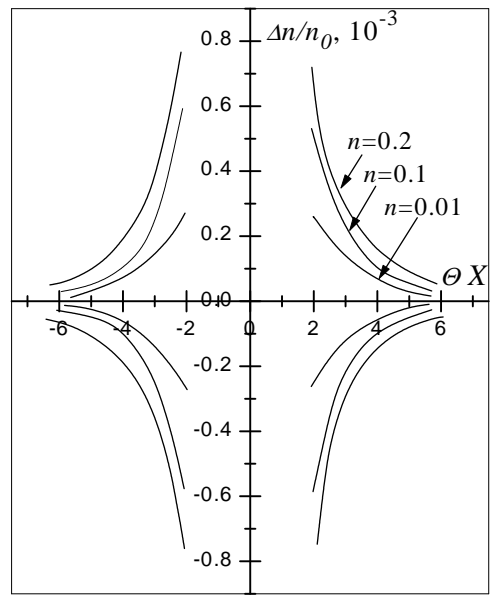

Figure 1. Coordinate electron distribution along the normal to the dislocation wall. (Upper and lower curves correspond to planes $y=(4 k-1) d / 4$ and $y=$ $(4 k+1) d / 4$, respectively. Here $k=0,1,2, \ldots)$.

The parameter of the resulting lattice deformation $U(|x|, y)$ (12) about the dislocation wall with the electron-deformation redistribution (29) takes the form

$$
U(|x|, y)=U_{a}(|x|) \sin (\Theta y),
$$

where

$$
\begin{gathered}
U_{a}(|x|)=-\frac{b}{d} \frac{1-2 \nu}{1-\nu}[\exp (-\Theta|x|) \\
\left.+\frac{\gamma \Theta}{\sqrt{\Theta^{2}+g^{2} / \varepsilon}} \exp \left(-|x| \sqrt{\Theta^{2}+g^{2} / \varepsilon}\right)\right],(31) \\
\gamma=S^{2} R_{S} / K
\end{gathered}
$$

In figure 1 we present the coordinate electron distribution around the dislocation wall at a different average carrier concentration, obtained at the values of the parameters typical of the crystalline systems with transition or rare earth elements.

Based on the results we come to the conclusions:

- redistribution of electrons along the dislocation wall has a periodic character. Normal to the plane with the wall, the concentration of the electrons falls going away from it. The falling occurs in the case of a unique dislocation as well but such a falling is slower, $\sim 1 / \rho$; 
- with the increase of band filling $n(0 \leqslant n \leqslant 2)$ both redistribution of electrons and lattice deformation induced by the dislocation wall become more localized to it;

- at the increase of the distance between the neighbouring dislocations in the dislocation wall dependence of the amplitude of the electron redistribution on the distance to the wall becomes smoother;

- from the estimation performed based on the formula (31) it follows that the electron part of the strain in the compound containing earth or transition elements may be of the order of $30 \%$ of the total strain.

\section{References}

1. Kovalenko A.V., Mekekeshko A.Yu. Resonance exciton luminescence of ZnSe/GaAs (100) films. // Ukr. Fiz. Zhurn., 1992, vol. 37, No. 12, p. 1802-1805 (in Russian).

2. Peleschak R.M., Lukiyanets B.A. Electron redistribution around a core of straight-line dislocation. // Pisma v ZhTF, 1998, vol. 24, No. 2, p. 37-41 (in Russian).

3. Friedel J. Dislocations. Moscow, Mir, 1967 (in Russian).

4. Hirt J., Lote I. Theory of Dislocations. Moscow, Mir, 1972 (in Russian).

5. Stasyuk I.V., Peleschak R.M. Electron state filling and deformation of the lattice near the boundary of regions with different mechanical strains. // Ukr. Fiz. Zhurn., 1991, vol. 36, No. 11, p. 1744-1749 (in Russian).

6. Landau L.D., Lifshits E.M. Theory of Elasticity. Moscow, Nauka, 1965 (in Russian).

7. Gabovich A.M. Electrostatic interaction dislocation walls in metals with point charged defects. // Fiz. Metallov i Metalloved., 1981, vol. 1, No. 5, p.1113-1116 (in Russian).

\section{Заповнення електронних станів і деформація гратки в околі стінки крайових дислокацій}

\section{Р.М.Пелещак}

Дрогобицький педагогічний університет ім. І.Франка, Львівська обл., 293720 Дрогобич, вул. І.Франка, 24

Отримано 1 березня 1999 р., в остаточному вигляді - 2 квітня $1999 \mathrm{p.}$

У рамках зонної моделі з врахуванням електрон-деформаційного зв'язку досліджено електронний перерозподіл в околі стінки дислокацій в залежності від ступеня заповнення $(0<\bar{n}<1)$ зон провідності. Показано, що зі збільшенням ступеня заповнення зони провідності $\bar{n}$ перерозподіл має більш локалізований в околі площини дислокацій характер. Встановлено, що збільшення відстані між сусідніми дислокаціями приводить до збільшення періоду зміни перерозподілу електронної густини $\Delta n$ вздовж розміщення стінки дислокацій, а зміна амплітуди електронного перерозподілу як функції відстані до площини дислокацій має при цьому більш плавний характер.

Ключові слова: електрон-деформаційна взаємодія, стінка дислокацій

PACS: 61.72.Lk, 68.35.-p, 68.55.Ln 